\section{Making morphine} work better

Two compounds boost morphine's painkilling effects when injected into mice.

Morphine and other opioids induce inflammation in the central nervous system, which can suppress pain relief and lead to opioid dependence. Hang Yin at the University of Colorado at Boulder and his team show that morphine causes inflammation by binding to the protein MD2, which, in turn, causes the protein to bind to an immunesystem receptor called TLR4. In cultured cells, this process activates TLR4 signalling and the release of inflammatory molecules.

Injecting mice with two synthetic compounds known to block MD2 binding to TLR4 enhanced morphineinduced analgesia. Interfering with TLR4 signalling could be a promising strategy for improving painkilling therapies, the authors say.

Proc. Natl Acad. Sci. USA http://dx.doi.org/10.1073/ pnas.1200130109 (2012)

\section{MARINE MICROBIOLOG}

\section{Microbe alliance} with gutless worm

Microbes that help a gutless worm to eat and to process waste have developed unusual metabolic pathways to meet their own needs.

The worm Olavius algarvensis - found in marine sea-grass beds off the coast of the Italian island of Elba - harbours five species of bacteria in its body wall. Manuel Kleiner of the Max Planck Institute for Marine Microbiology in Bremen, Germany, and his colleagues identified and analysed 2,819 proteins and 97 metabolites produced by the worm or its associated bacteria. On the basis of their analyses, the authors propose that the bacteria generate energy for themselves using carbon monoxide and hydrogen from the surrounding sediment, and produce proteins that allow them to recycle waste products from the worm.

Proc. Natl Acad. Sci. USA

http://dx.doi.org/10.1073/

pnas.1121198109 (2012)

GEOSCIENCE

\section{Methane from the} Arctic Ocean

The Arctic Ocean seems to be emitting substantial amounts of methane, an important human-influenced greenhouse gas.

Eric Kort, now at NASA's Jet Propulsion Laboratory in Pasadena, California, and his team measured atmospheric methane levels during five flights over the Arctic carried out in 2009 and 2010. They detected high methane levels near the ocean surface that were not accompanied by high carbon monoxide levels, indicating that the methane did not arise from combustion. The researchers estimate that the methane-emission rate is similar to that seen off the coast of Siberia and attributed to melting permafrost.

Because high methane levels were observed over open water near sea ice, the authors say that Arctic Ocean methane emissions may increase as more sea ice melts.

Nature Geosci. http://dx.doi. org/10.1038/ngeo1452 (2012)

\section{MICROBIOLOGY \\ How gut flora can turn deadly}

Resident gut bacteria can cause disease if the balance of gut microflora is disrupted, for example, by antibiotics. Researchers at the University of California, Berkeley, show that a strain of gut Escherichia coli can cause sepsis in antibiotictreated mice by triggering excessive inflammation.

Janelle Ayres and her colleagues gave mice a cocktail of antibiotics and a gutinjuring chemical. The animals soon showed hypothermia

COMMUNITY CHOICE

The most viewed papers in science

\title{
Arctic heat link to weather extremes
}

\section{- HIGHLY READ \\ on www.agu.org 17 Mar-16 Apr}

The Arctic is warming faster than the rest of the Northern Hemisphere; this could be increasing the likelihood of extreme weather events in mid-latitude regions by altering

the circulation of air currents in the upper atmosphere.

Jennifer Francis at Rutgers University in New Brunswick, New Jersey, and Stephen Vavrus at the University of WisconsinMadison studied changes in 'Rossby waves' - large northsouth meanders in high-altitude winds. The authors detected a slowed eastward movement of Rossby waves in a fast-flowing air current called the jet stream, and identified two contributing factors: weaker west-to-east winds and increased wave amplitude. Both of these seem to be linked to earlier spring snow-melt on high-latitude land and to sea-ice loss in summer - two likely consequences of enhanced Arctic warming.

A slowing of jet-stream waves that influence weather leads to more persistent weather patterns in the mid-latitudes. This could raise the likelihood of drought, flooding, cold snaps and heatwaves.

Geophys. Res. Lett. http://dx.doi.org/10.1029/2012GL051000 (2012) and multiple organ damage - signs of sepsis. A strain of antibiotic-resistant E. coli isolated from these mice caused disease when injected into normal animals.

This E. coli strain seems to cause sepsis by activating protein complexes called inflammasomes, which can stimulate excessive inflammation in the presence of pathogens.

Nature Med. http://dx.doi. org/10.1038/nm.2729 (2012)

\section{STEM CELLS \\ Patient-specific heart cells}

Using skin cells from a family with a cardiac disorder, researchers have generated

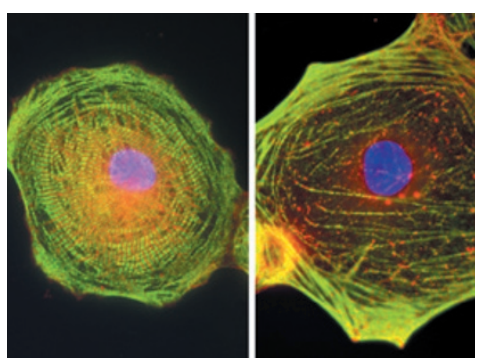

heart cells that reveal some of the defects underlying the disease.

Joseph Wu and his colleagues at Stanford University in California took skin cells from family members with and without dilated cardiomyopathy, a common cause of heart failure, and reprogrammed them into stem cells. The authors then used cardiac growth factors to turn the stem cells into heart cells. Compared with cells derived from healthy individuals (pictured left), heart cells from patients with dilated cardiomyopathy (right) showed a decreased ability to contract and an abnormal distribution of a filament protein called $\alpha$-actinin (shown in red), which has a key role in cell contraction.

Cells from the patients functioned better after being treated with a drug often given to cardiac patients.

Sci. Transl Med. 4, 130ra47 (2012)

\section{- NATURE.COM}

For the latest research published by Naturevisit:

www.nature.com/latestresearch 